\title{
Regulation of LOXL2 and SERPINH1 by antitumor microRNA-29a in lung cancer with idiopathic pulmonary fibrosis
}

\author{
Kazuto Kamikawaji ${ }^{1}$, Naohiko Seki ${ }^{2}$, Masaki Watanabe ${ }^{1}$, Hiroko Mataki ${ }^{1}$, Tomohiro Kumamoto ${ }^{1}$, \\ Koichiro Takagi ${ }^{1}$, Keiko Mizuno ${ }^{1}$ and Hiromasa Inoue ${ }^{1}$
}

Idiopathic pulmonary fibrosis (IPF) is a chronic, progressive lung disease that is refractory to treatment and carries a high mortality rate. IPF is frequently associated with lung cancer. Identification of molecular targets involved in both diseases may elucidate novel molecular mechanisms contributing to their pathology. Recent studies of microRNA (miRNA) expression signatures showed that microRNA-29a (miR-29a) was downregulated in IPF and lung cancer. The aim of this study was to investigate the functional significance of $m i R-29 a$ in lung cancer cells (A549 and EBC-1) and lung fibroblasts (MRC-5) and to identify molecular targets modulated by miR-29a in these cells. We confirmed the downregulation of miR-29a in clinical specimens of IPF and lung cancer. Restoration of $m i R-29 a$ suppressed cancer cell aggressiveness and fibroblast migration. A combination of gene expression data and in silico analysis showed that a total of 24 genes were putative targets of miR-29a. Among them, lysyl oxidase-like 2 (LOXL2) and serpin peptidase inhibitor clade $\mathrm{H}$, member 1 (SERPINH1) were direct targets of miR-29a by luciferase reporter assays. The functions of LOXL2 and SERPINH1 contribute significantly to collagen biosynthesis. Overexpression of LOXL2 and SERPINH1 was observed in clinical specimens of lung cancer and fibrotic lesions. Downregulation of miR-29a caused overexpression of LOXL2 and SERPINH1 in lung cancer and IPF, suggesting that these genes are involved in the pathogenesis of these two diseases.

Journal of Human Genetics (2016) 61, 985-993; doi:10.1038/jhg.2016.99; published online 4 August 2016

\section{INTRODUCTION}

Idiopathic pulmonary fibrosis (IPF) is a chronic, progressive parenchymal lung disease characterized by chronic tissue damage and aberrant wound healing and is associated with severe pathologic changes in the structure of the alveoli. ${ }^{1}$ There are limited effective therapeutic options for IPF and patients inevitably succumb to the disease., ${ }^{2,3}$ Although pirfenidone and nintedanib reduce the rate at which forced vital capacity declines, their impact on long-term mortality remains unclear.

Another pulmonary disease, lung cancer is the leading cause of cancer-related death in developed countries. ${ }^{4}$ Approximately $80 \%$ of lung cancers are classified histopathologically as non-small cell lung cancers (NSCLC), and the majority of advanced NSCLC patients dying in less than 5 years despite the use of various combination chemotherapy, chemoradiotherapy or molecularly targeted therapy. ${ }^{5}$ Interestingly, NSCLC and IPF share common risk factors, such as smoking, environmental or professional exposure, viral infections, and chronic tissue injury. ${ }^{6,7}$ Indeed, the risk of developing lung cancer is seven times higher in patients with IPF. ${ }^{8}$ These findings suggest that there are common driver genes and molecular pathways in the two diseases.

The discovery of RNAs that do not code for proteins has provided new directions in the study of human pathogenesis. In this regard, microRNAs (miRNAs) are particularly important. miRNAs are small non-coding RNAs that have pivotal roles in the regulated expression of protein coding/non-coding RNAs. Regulation of gene expression is achieved by repressing the translation of mRNAs or cleaving RNA transcripts in a sequence-specific manner. ${ }^{9,10}$ Thus, one miRNA species can regulate the amount of a specific mRNA in human cells. ${ }^{10,11}$ Aberrantly expressed miRNAs can disrupt the regulated RNA networks in normal cells, thereby promoting pathologic development and cancer. Many studies have shown that miRNAs are aberrantly expressed in lung cancers and in IPF. ${ }^{12-16}$ We hypothesized that the identification of aberrantly expressed miRNAs is an important step toward elucidating miRNA-regulated molecular targets and miRNAmediated pathogenic RNA networks that contribute to lung cancers and pulmonary fibrosis.

\footnotetext{
${ }^{1}$ Department of Pulmonary Medicine, Graduate School of Medical and Dental Sciences, Kagoshima University, Kagoshima, Japan and ${ }^{2}$ Department of Functional Genomics, Chiba University Graduate School of Medicine, Chiba, Japan

Correspondence: Professor H Inoue, Department of Pulmonary Medicine, Graduate School of Medical and Dental Sciences, Kagoshima University, 8-35-1 Sakuragaoka, Kagoshima 890-8520, Japan.

E-mail: inoue-pulm@umin.net

Received 2 April 2016; revised 24 June 2016; accepted 5 July 2016; published online 4 August 2016
} 


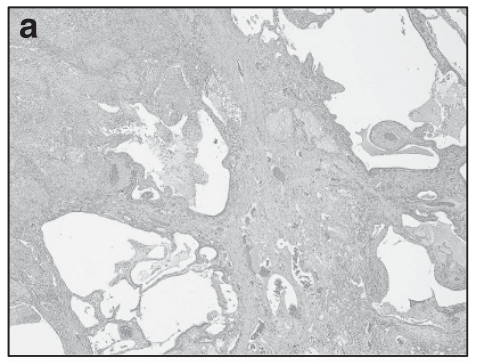

c
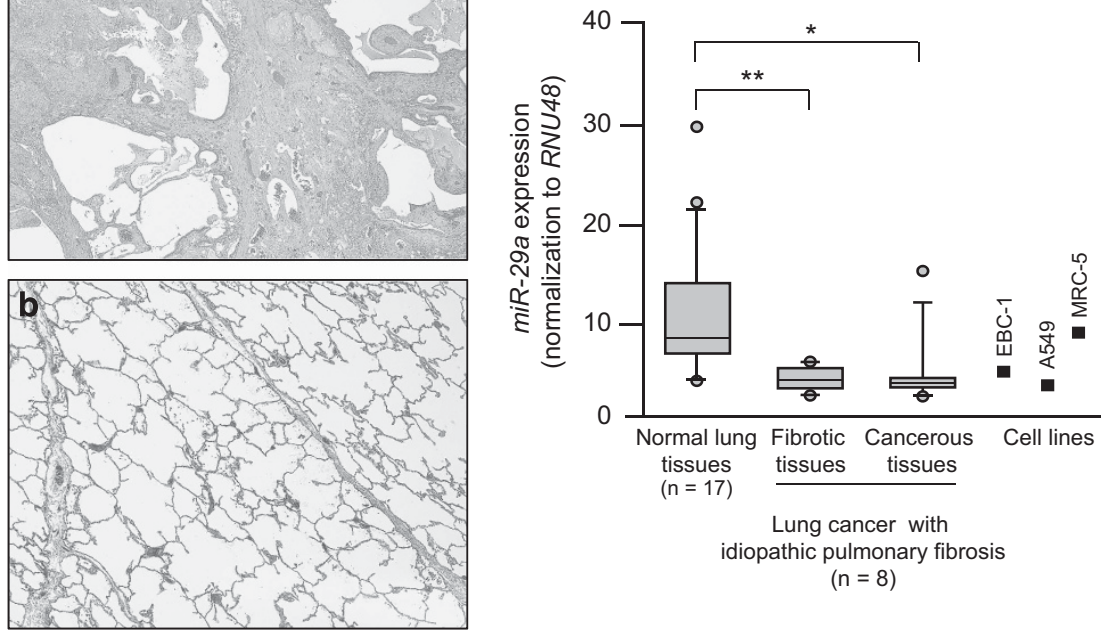

Figure 1 Comparison of expression levels of miR-29a in clinical specimens and cell lines. (a) Typical specimen of lung cancer with idiopathic pulmonary fibrosis (IPF). (b) Normal lung tissue. (c) Expression levels of miR-29a in lung cancer, IPF, normal lung tissues and cell lines. ${ }^{*} P<0.05$, ${ }^{* *} P<0.005$. A full color version of this figure is available at the Journal of Human Genetics journal online.

Table 1A Characteristics of the patients

\begin{tabular}{|c|c|c|}
\hline Lung cancer & $n$ & (\%) \\
\hline $\begin{array}{l}\text { Total number } \\
\text { Median age (range) }\end{array}$ & $\begin{array}{c}8 \\
73.5(69-89)\end{array}$ & \\
\hline $\begin{array}{l}\text { Gender } \\
\text { Male } \\
\text { Female }\end{array}$ & $\begin{array}{l}5 \\
3\end{array}$ & $\begin{array}{l}(62.5) \\
(37.5)\end{array}$ \\
\hline $\begin{array}{l}\text { Tissue types } \\
\text { Adeno } \\
\text { Sq }\end{array}$ & $\begin{array}{l}4 \\
4\end{array}$ & $\begin{array}{l}(50.0) \\
(50.0)\end{array}$ \\
\hline $\begin{array}{l}\text { Pathological tumor } \\
\text { IA } \\
\text { IB } \\
\text { IIA } \\
\text { IIB } \\
\text { IIIA } \\
\text { IIIB }\end{array}$ & $\begin{array}{l}3 \\
2 \\
0 \\
1 \\
2 \\
0\end{array}$ & $\begin{array}{l}(37.5) \\
(25.0) \\
(12.5) \\
(25.0)\end{array}$ \\
\hline $\begin{array}{l}\text { Differentiation } \\
\text { Well } \\
\text { Moderately } \\
\text { Poorly }\end{array}$ & $\begin{array}{l}1 \\
6 \\
1\end{array}$ & $\begin{array}{l}(12.5) \\
(75.0) \\
(12.5)\end{array}$ \\
\hline $\begin{array}{l}\text { Pleural invasion } \\
\begin{array}{l}(+) \\
(-)\end{array}\end{array}$ & $\begin{array}{l}3 \\
5\end{array}$ & $\begin{array}{l}(37.5) \\
(62.5)\end{array}$ \\
\hline $\begin{array}{l}\text { Venous invasion } \\
\qquad(+) \\
(-)\end{array}$ & $\begin{array}{l}0 \\
8\end{array}$ & (100.0) \\
\hline $\begin{array}{l}\text { Lymphatic invasion } \\
\begin{array}{l}(+) \\
(-)\end{array}\end{array}$ & $\begin{array}{l}4 \\
4\end{array}$ & $\begin{array}{l}(50.0) \\
(50.0)\end{array}$ \\
\hline $\begin{array}{l}\text { Recurrence } \\
(+) \\
(-)\end{array}$ & $\begin{array}{l}6 \\
2\end{array}$ & $\begin{array}{l}(75.0) \\
(25.0)\end{array}$ \\
\hline
\end{tabular}

Based on this proposal, we have sequentially identified tumorsuppressive miRNAs and novel miRNA-mediated RNA networks in lung cancer cells by establishing miRNA expression signatures. For
Table 1B Normal lung tissue

\begin{tabular}{lc}
\hline Normal lung tissue & $\mathrm{n}$ \\
\hline $\begin{array}{l}\text { Total number } \\
\text { Median age (range) }\end{array}$ & 17 \\
$\begin{array}{l}\text { Gender } \\
\text { Male }\end{array}$ & \\
\hline
\end{tabular}

example, $m i R-1$ and $m i R-133 a$ inhibit cancer cell migration and invasion through targeting colonin-1, which is involved in a variety of cellular processes. Restoration of miR-206 suppressed cancer cell aggressiveness via its regulation of EGFR and $c$-MET oncogenic signaling. ${ }^{17}$ More recently, we demonstrated that the miR-29 family is significantly downregulated in several types of cancers, including lung squamous cell carcinoma cells. These miRNAs act as antitumor miRNAs through their regulation of several extracellular matrix (ECM) components. ${ }^{18-23}$ In cancer cells, aberrantly expressed ECMmediated oncogenic signals trigger cancer cell migration and invasion and promote metastasis. ${ }^{24,25}$ Fibrosis is enhanced by excess stiffness of ECM components, and overexpression of ECM components replaces functional tissue and disrupts organ architecture. ${ }^{26,27}$ These observations suggest that the $m i R$-29-family may also have important roles in the pathogenesis of pulmonary fibrosis.

In this study, we focused on miR-29a and investigated its functional significance in lung cancer and IPF. We attempted to identify the genes targeted by $m i R-29 a$ and how they contributed to pathologic changes. The discovery of $m i R-29 a$-regulated genes provides new insight into the potential molecular pathogenesis of these two diseases.

\section{MATERIALS AND METHODS}

\section{Clinical specimens and RNA extraction}

A total of eight specimens of lung cancer with IPF and 17 normal lung tissues that obtained from lung cancer patients who underwent surgery at Kagoshima 

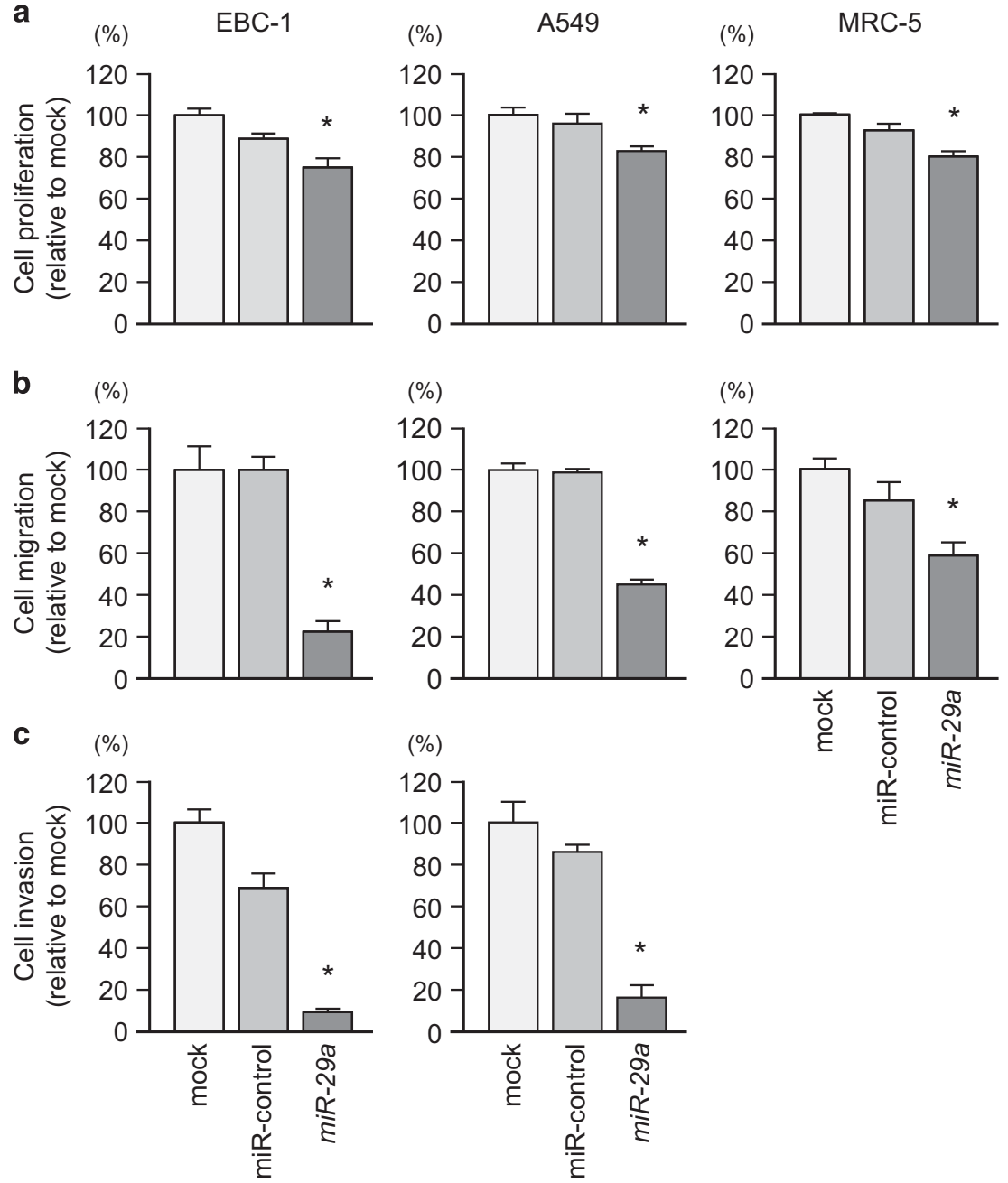

Figure 2 Effects of miR-29a transfection on EBC-1, A549 and MRC-5 cells. (a) Cell proliferation was determined with XTT assays $96 \mathrm{~h}$ after transfection with $10 \mathrm{~nm}$ miR-29a, miR-control or mock. (b) Cell migration activity was determined by migration assay $48 \mathrm{~h}$ after transfection. (c) Cell invasion activity was determined by Matrigel invasion assay $72 \mathrm{~h}$ after transfection. ${ }^{*} P<0.05$.

University Hospital (Kagoshima, Japan) from 2010 to 2013. IPF was diagnosed according to the official ATS/ERS/JRS/ALAT statement. ${ }^{2}$ Formalin-fixed paraffin-embedded tissue sections were used for quantitative real-time RTPCR analysis and immunohistochemical staining.

Samples were staged according to the TNM classification for lung cancer and were histologically graded. ${ }^{28}$ Our studies were approved by the Institutional Review Board of Kagoshima University (IRB number 25-180). Prior written informed consent and approval were provided by each patient.

Total RNA (including miRNA) was extracted from tissues as previously described. ${ }^{18,29}$ The RNA integrity was assessed using the RNA 6000 Nano Assay Kit and a 2100 Bioanalyzer (Agilent Technologies, Santa Clara, CA, USA).

\section{Cell culture}

The EBC-1 and A549 human lung cancer cell lines and MRC-5 fibroblast cell line were obtained from the Japanese Collection of Research Bioresources Cell Bank (Osaka, Japan). The cell lines were maintained in RPMI 1640 medium or Eagle's minimum essential medium supplemented with $10 \%$ fetal bovine serum.

\section{Quantitative real-time PCR analysis}

Quantitative Taqman real-time PCR analysis was used to evaluate lysyl oxidaselike 2 (LOXL2) and serpin peptidase inhibitor clade $\mathrm{H}$, member 1 (SERPINH1)
mRNA expression levels. Primers and probes were assay-on-demand gene expression products: LOXL2 (P/N: Hs00158757_m1, Applied Biosystems, Foster City, CA, USA), SERPINH1 (P/N: Hs01060397_m1, Applied Biosystems). Stem-loop RT-PCR for miR-29a (P/N: 002112, Applied Biosystems) was used to quantify the expression levels of miRNAs according to the manufacturer's protocol. Quantitative Taqman real-time PCR relative to human GAPDH (P/N: Hs02758991_ml; Applied Biosystems) and RNU48 (P/N: 440888; Applied Biosystems) as the internal controls were performed to assess the expression levels of mRNA and miRNAs in the sample, using the deltadelta Ct method.

\section{Restoration and inhibition of $m i R-29 a$}

Transfection was performed as described previously. ${ }^{17,29}$ We used Pre-miR-29a miRNA precursors (P/N: AM 17100; Applied Biosystems), miR-29a inhibitor (P/N: AM 4464084; Applied Biosystems) and negative-control miRNA (P/N: AM 17111; Applied Biosystems).

\section{Cell proliferation, migration and invasion assays}

Cell proliferation, migration and invasion assays were performed as described before. ${ }^{18}$ All experiments were performed in triplicate. 


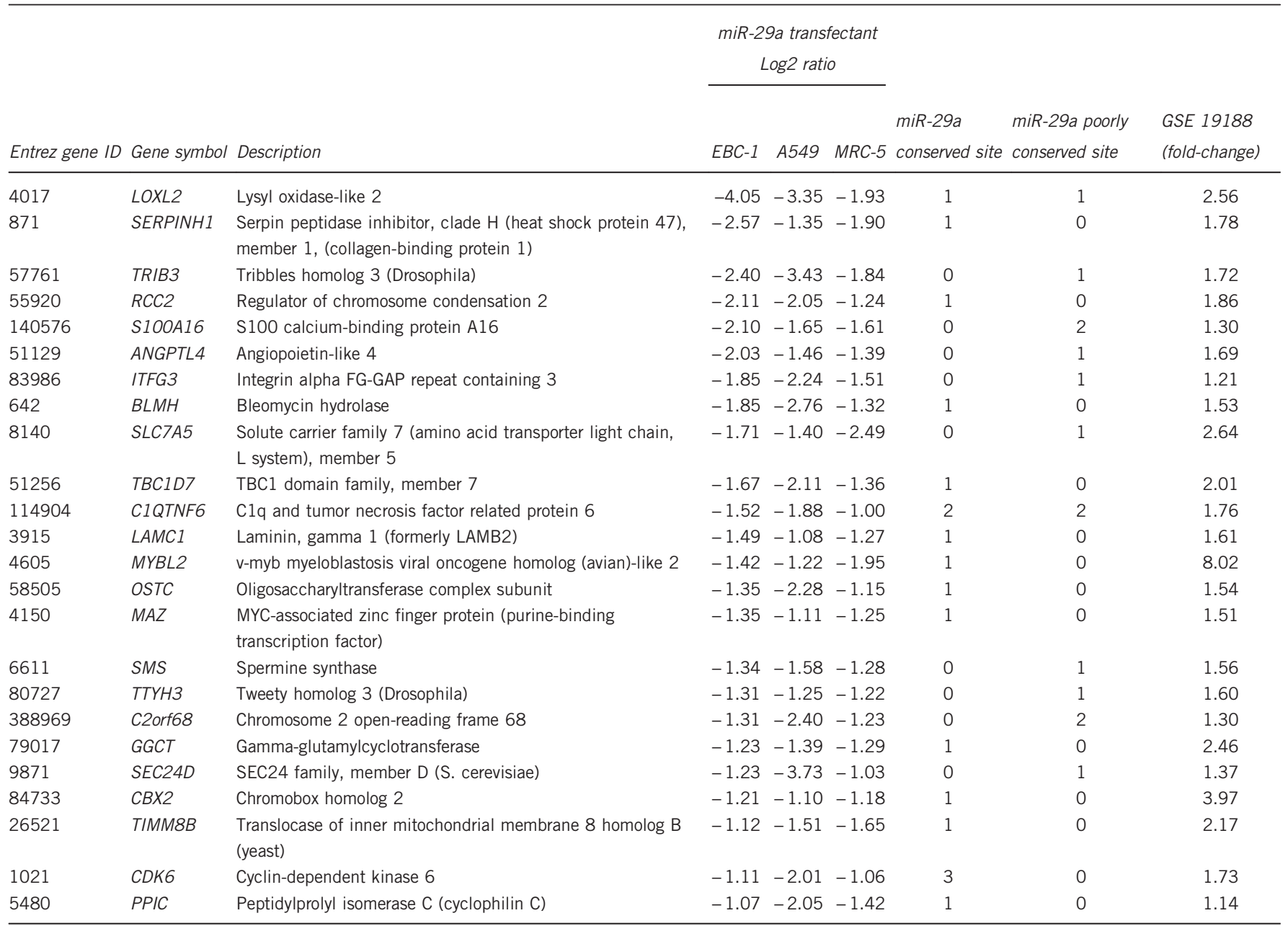

\section{Identification of putative target genes of $m i R-29 a$}

TargetScan database (http://www.targetscan.org) was used to identify miR-29a target genes. In addition, we performed gene expression analysis using miR-29a-transfected cells (EBC-1, A549 and MRC-5). Oligo-microarray human $60 \mathrm{Kv}$ (Agilent Technologies) was used for gene expression studies. To investigate the expression status of candidate miR-29a target genes in NSCLC clinical specimens, we analyzed gene expression profiles in the gene expression omnibus database (accession number: GSE 19188). Microarray procedures and data mining methods were described previously. ${ }^{18,29}$

\section{Western analysis}

Expression of LOXL2 and SEPINH1 protein in vitro was assessed using western analysis as described previously. ${ }^{17,29}$ Immunoblotting was done with anti-LOXL2 antibody (1:1000; ab96233; Abcam, Cambridge, UK) or with anti-SERPINH1 antibody (1:500; sc-5293; Santa Cruz Biotechnology, Santa Cruz, CA, USA) and anti-GAPDH antibody (1:10000; MAB374; Chemicon, Temecula, CA, USA).

\section{Plasmid construction and dual-luciferase reporter assays}

Partial wild-type sequences of the $3^{\prime}$-untranslated region (UTR) of LOXL2 and SERPINH1 or those with a deleted miR-29a target site (positions 555-561 or 757-763 of LOXL2 3'-UTR and 57-63 of SERPINH1 3'-UTR) were inserted between the XhoI and PmeI restriction sites in the $3^{\prime}$-UTR of the hRluc gene in the psiCHECK-2 vector (C8021; Promega, Madison, WI, USA). Dual-luciferase reporter assay was performed as described previously. ${ }^{17,29}$

\section{Immunohistochemistry}

Formalin-fixed paraffin-embedded tissue sections were treated as previously described. ${ }^{17}$ Anti-LOXL2 rabbit polyclonal antibody (ab96233; Abcam) and anti-SERPINH1 mouse monoclonal antibody (sc-5293; Santa Cruz Biotechnology) were used.

\section{Statistical analysis}

All data are shown as mean \pm s.e. Statistical comparison was made by analysis of variance, followed by Bonferroni's post hoc analysis. Expert StatView software, version 4 (SAS Institute, Cary, NC, USA), was used in these analyses.

\section{RESULTS}

Expression levels of $m i R-29 a$ in lung cancer, IPF and normal lung tissues

The expression level of $m i R-29 a$ was evaluated by quantitative realtime PCR methods by using formalin-fixed paraffin-embedded specimens of lung cancer lesions, fibrotic lesions and normal lung tissues. Representative formalin-fixed paraffin-embedded specimens are shown in Figures 1a and b. The patient backgrounds and clinicopathological characteristics are summarized in Tables $1 \mathrm{~A}$ and $1 \mathrm{~B}$. The expression level of $m i R-29 a$ was significantly reduced in lung cancer and fibrotic lesions compared with normal lung tissues (Figure 1c). 


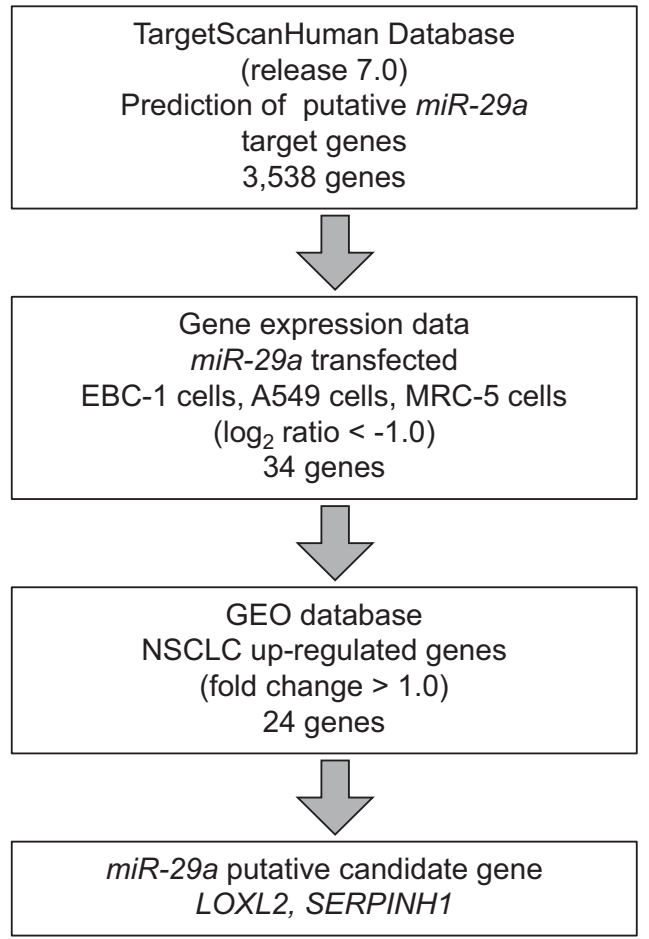

Figure 3 Flow chart illustrating the strategy for identification of miR-29a target genes. In total, 3538 genes were identified as putative targets of miR-29a according to the TargetScan database. We merged the expression analysis data of downregulated genes in miR-29a-transfected EBC-1, A549 and MRC-5 cells ( $\log _{2}$ ratio $<-1.0$ ). Upregulated genes were determined according to the gene expression data set of lung NSCLC clinical specimens according to the GEO database (accession no. GSE 19188). From this selection, 24 candidate genes were identified as putative targets of the miR-29a.

Effects of $m i R-29 a$ restoration on the proliferation, migration and invasion of NSCLC cell lines and a fibroblast cell line

To evaluate the functional roles of $m i R-29 a$, we carried out gain-of-function studies using mature miRNA transfection into two NSCLC cell lines (EBC-1 and A549) and a fibroblast cell line (MRC-5).

The XTT assays revealed inhibition of cell proliferation in EBC-1, A549 and MRC-5 cells transfected with $m i R-29 a$ in comparison with mock- or control-transfected cells (Figure 2a). The woundhealing assays showed significant inhibition of cell migration activities in miR-29a transfectants (EBC-1, A549 and MRC-5) compared with that in mock- or miR-control-transfected cells (Figure 2b). Moreover, Matrigel invasion assays demonstrated that miR-29a transfection significantly inhibited cell invasion. The number of invading cells was significantly reduced in miR-29a transfected EBC-1 and A549 cells (Figure 2c). In this assay, we omitted examination of MRC-5 cells because the ability for invasion of this cell line is extremely low.

In contrast to restoration study, inhibition of $m i R-29 a$ enhanced EBC-1 cell proliferation, migration and invasion (Supplementary Figure 1).

Identification of putative $m i R-29 a$ regulated genes in lung cancer and fibroblast cells

To identify $m i R$-29a-regulated genes, we carried out a combination of in silico analysis and genome-wide gene expression analysis of miR-29a transfectant cells (EBC-1, A549 and MRC-5). By using TargetScan database analysis, a total of 3538 genes were identified as putative $m i R-29 a$-regulated genes, that is, those that had putative target sites for $m i R-29 a$ in their $3^{\prime}$-UTRs. We undertook genome-wide gene expression analysis using EBC-1, A549 and MRC-5 cells. Among the 3538 genes, we selected a total of 34 genes that were commonly downregulated in EBC-1, A549 and MRC-5 cells (average $\log _{2}$ ratio $<-1.0$ ) following $m i R-29 a$ transfection compared with the expression levels in mock cells. Finally, we investigated the expression status of those 34 genes in lung cancer specimens by using the gene expression omnibus database (accession number: GSE 19188). From this selection, 24 candidate genes were identified as targets of $m i R-29 a$ (Table 2).

Extracellular matrix has a key role in the progression of cancer and fibrosis (24-27). Therefore, we focused on the ECM-related genes.

Among these candidate genes, we chose LOXL2 and SERPINH1 genes that code for collagen cross-linking enzymes and those genes were subjected to further analyses. Our method for selecting miR-29a target genes is shown in Figure 3.

\section{Direct regulation of $L O X L 2$ and SERPINH1 by $m i R-29 a$ in lung cancer cells and fibroblasts}

We conducted qRT-PCR and western blotting to confirm that restoration of $m i R-29 a$ resulted in downregulation of LOXL2 and SERPINH1 in EBC-1, A549 and MRC-5 cells. The mRNA and protein expression levels of LOXL2 and SERPINH1 were significantly repressed in $m i R-29 a$ transfectants compared with mock or miR-control transfectants in EBC-1, A549 and MRC-5 (Figures $4 \mathrm{a}$ and $\mathrm{b}$ ). In contrast to restoration study, inhibition of $m i R-29 a$ resulted in upregulation of LOXL2 and SERPINH1 in these cells (Supplementary Figure 2).

Next, we performed dual-luciferase reporter assays in A549 cells to confirm whether LOXL2 and SERPINH1 mRNAs were directly regulated by $m i R-29 a$. The TargetScan database predicted that putative miR-29a-binding sites existed in the $3^{\prime}$-UTRs of LOXL2 (positions 555-561 and 757-763; Figure 5a) and SERPINH1 (position 57-63; Figure 5b). We used vectors encoding either the partial wild-type sequence of the $3^{\prime}$-UTR of LOXL2 or SERPINH1 mRNA, including the predicted miR-29a target sites, or deletion vectors lacking the miR-29a target sites. We found that the luminescence intensities were significantly reduced by transfection with $m i R-29 a$ and vectors carrying the wild-type $3^{\prime}$-UTR of LOXL2 and SERPINH1, whereas transfection with deletion vectors blocked the decrease in luminescence (Figure 5). These data suggested that $m i R-29 a$ bound directly to specific sites in the $3^{\prime}$-UTRs of LOXL2 and SERPINH1 mRNA.

Expression of LOXL2 and SERPINH1 in clinical specimens of lung cancer with IPF

We used immunohistochemical staining to examine the expression status of LOXL2 and SERPINH1 in clinical specimens of lung cancer with associated IPF (Figures 6a and b). LOXL2 was strongly expressed in cancer cells and fibroblasts (Figures $6 c$ and d). Similar overexpression of SERPINH1 was observed in cancer cells and fibroblasts (Figures $6 e$ and $\mathrm{f}$ ).

\section{DISCUSSION}

Our present study showed that expression of $m i R-29 a$ was significantly reduced in lung cancer tissues and in fibrotic lesions of IPF and that restoration of miR-29a significantly suppressed proliferation, 

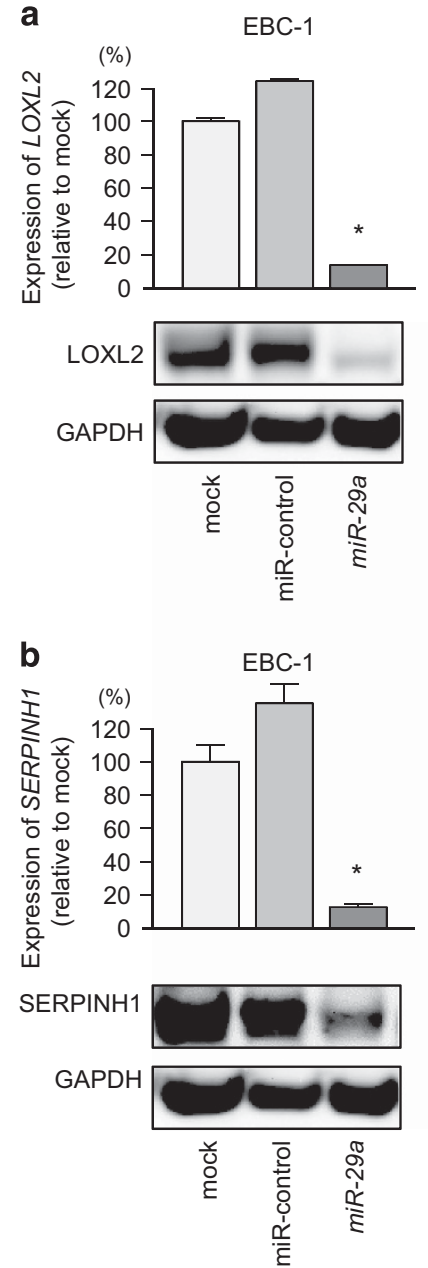
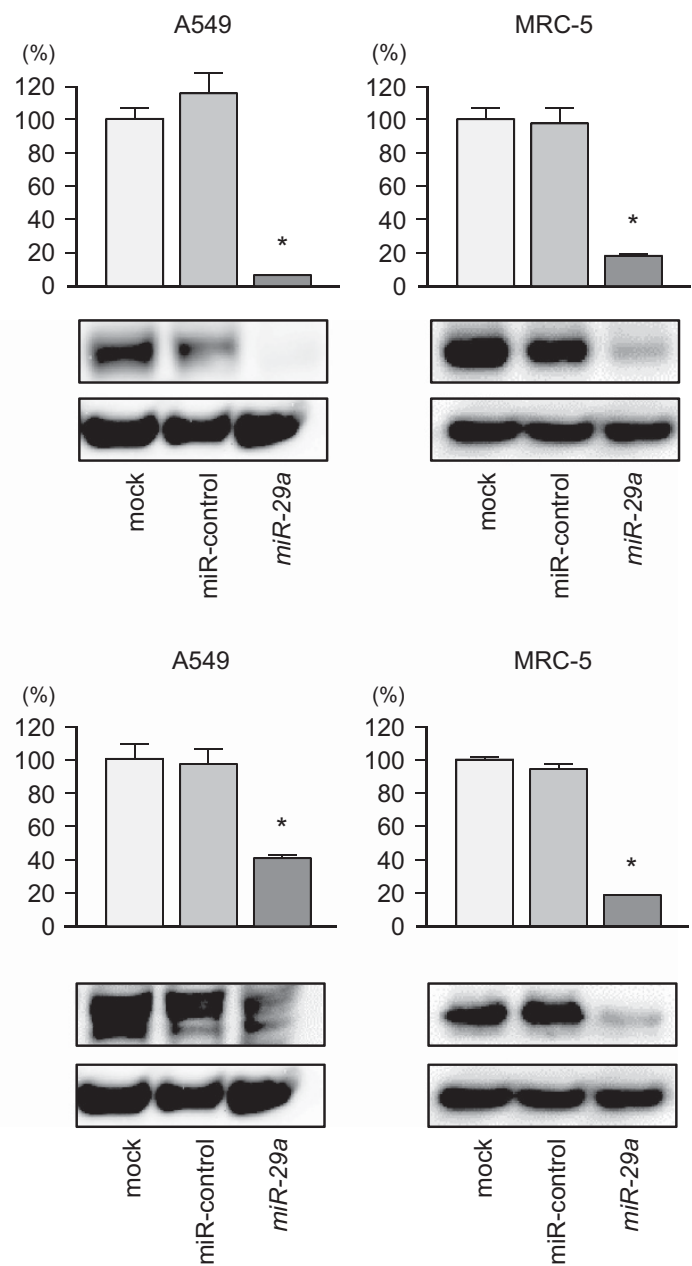

Figure 4 Effects of miR-29a transfection on LOXL2 and SERPINH1 expression in EBC-1, A549 and MRC-5 cells. (a, bar graph) LOXL2 mRNA expression $72 \mathrm{~h}$ after transfection with miR-29a. GAPDH was used as an internal control. (a, blot) LOXL2 protein expression $72 \mathrm{~h}$ after transfection with miR-29a. GAPDH was used as a loading control. (b, bar graph) SERPINH1 mRNA expression $72 \mathrm{~h}$ after transfection with miR-29a. (b, blot) SERPINH1 protein expression $72 \mathrm{~h}$ after transfection with $m i R-29 \mathrm{a} .{ }^{*} P<0.0001$.

migration and invasion in cancer cells and fibroblasts. Those data suggested that $m i R-29 a$ and $m i R-29 a$-regulated genes were deeply involved in these diseases. Our recent studies of cancer cells showed that all members of the miR-29-family were downregulated in several types of cancer tissues and that restoration of these miRNAs inhibited cancer cell aggressiveness through targeting collagen biosynthesis genes, laminins and integrins. ${ }^{30}$ Most types of cells require ECMintegrin-mediated signaling pathways for proliferation, migration, invasion and survival. ${ }^{31,32}$ Aberrant expression of ECM-related genes disturbs tightly regulated integrin-meditated signaling and these phenomena promote cancer cell aggressiveness. ${ }^{30}$ Thus, elucidation of tumor-suppressive miRNAs that regulate novel ECM-related pathways should point to new therapies for cancer.

Recent studies have indicated that dysregulated miRNAs contribute to the disruption of normal cellular RNA networks, promoting the development of cancer cells and associated pathology. We have identified novel miRNA-regulated cancer pathways based on the aberrant expression of miRNAs. ${ }^{17,18,33}$ In this study, we identified $m i R-29 a$-regulated genes that participate in the pathogenesis of lung cancer and IPF.
Basically, the function of LOXL2 is covalent cross-linking of collagen and/or elastin in the ECM. ${ }^{34,35}$ Recent studies of cancer cells showed that aberrant expression of LOXL2 was correlated with disease progression and aggressiveness in several types of cancers. ${ }^{35}$ Our present data indicated that overexpression of LOXL2 enhanced cancer cell migration and invasion in several cancers. ${ }^{18,36,37}$ SERPINH1 (also known as HSP47) is a $47 \mathrm{kDa}$ collagen-binding glycoprotein localized in the endoplasmic reticulum (ER) and as a collagen-specific molecular chaperon. ${ }^{38}$ Many studies have reported that SERPINH1 is overexpressed in cancers and fibrotic diseases. ${ }^{39-41}$ To our surprise, our past studies demonstrated that LOXL2 was involved in cancer cell metastasis and directly regulated by the miR-29-family in renal cell carcinoma, head and neck cancer and lung squamous cell carcinoma. ${ }^{18,36,37}$ Moreover, SERPINH1 was regulated by miR-29a in cervical cancer. ${ }^{23}$ Our present data showed that both LOXL2 and SERPINH1 were directly regulated by $m i R-29 a$ in lung cancer cells and fibroblasts. These findings indicated that direct regulation of LOXL2 and SERPINH1 by miR-29a is widespread and indispensable for the normal function of the cells.

Fibrosis is caused by excess accumulation of ECM components, such as collagens, fibronectins, elastin and alpha-smooth muscle 
a

LOXL2 position 555-561
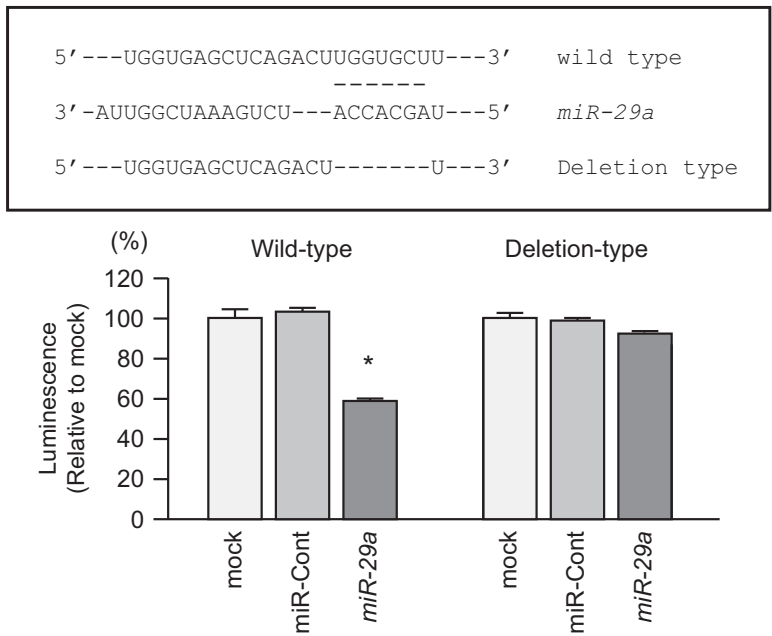

LOXL2 position $757-763$ b

SERPINH1 position 57-63
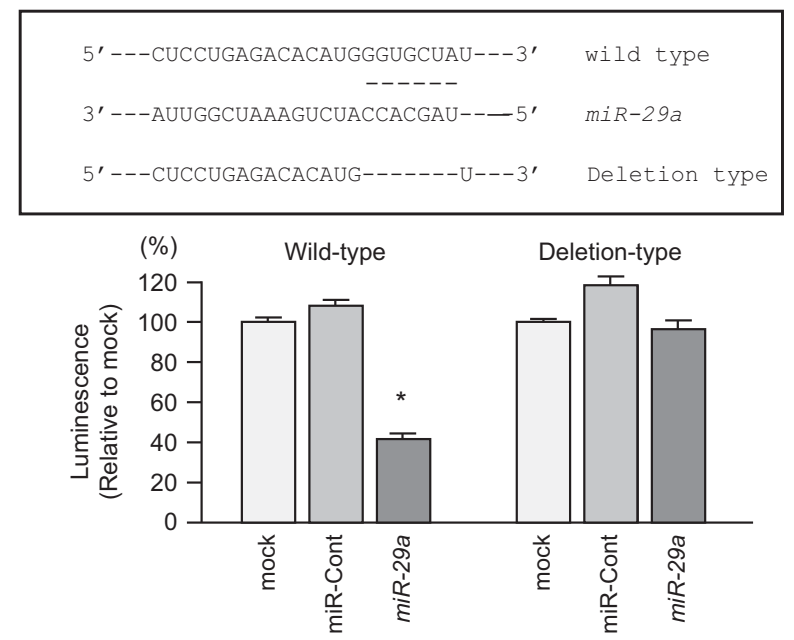

$$
\begin{aligned}
& \text { 5'-GguUUUUGAUUCAAC--GgUGCUAU---3' wild type } \\
& 3^{\prime}--- \text { AUUGGCUAAAGUCUACCACGAU---- } 5^{\prime} \quad m i R-29 a \\
& \text { 5'-GGUUUUUGAUUCAAC--------AU---3' Deletion type }
\end{aligned}
$$

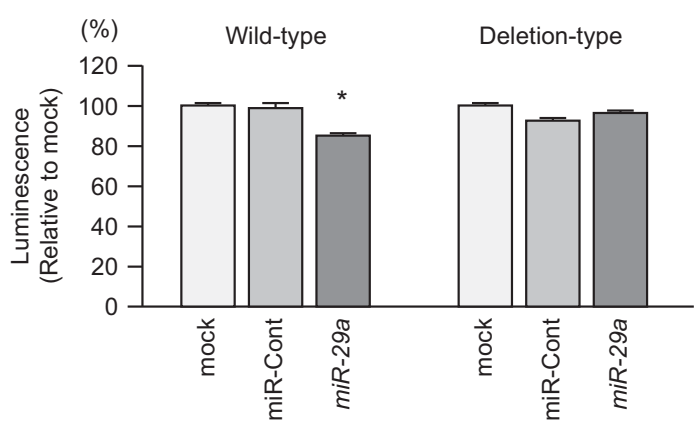

Figure 5 Direct regulation of LOXL2 and SERPINH1 by miR-29a in A549 cells. (a) The miR-29a-binding site in the 3'-UTR of LOXL2 mRNA. Luciferase reporter assays used vectors that included (WT) or lacked (DEL) wild-type sequences of the putative miR-29a target sites at position 555-561 and 757-763. Renilla luciferase values were normalized to firefly luciferase values. (b) The miR-29a-binding site in the 3'-UTR of SERPINH1 mRNA. Luciferase reporter assays used vectors that included (WT) or lacked (DEL) wild-type sequences of the putative miR-29a target sites at position $57-63$. ${ }^{*} P<0.001$.

actin. ECM-related genes also contribute to the development of fibrosis. ${ }^{26,27,42}$ Recent studies reported that members of the miR-29-family have potential roles in the inhibition of ECM synthesis, indicating anti-fibrotic activity. ${ }^{43,44}$ Interestingly, the search for miR-29 family targets by in silico analysis revealed that many collagen genes and several ECM component genes were putative targets of $m i R-29$. Downregulation of the $m i R-29$ family was demonstrated in several types of human fibrotic tissues, including IPF, ${ }^{13,15,45,46}$ supporting our present findings. It would be important to confirm the downregulation of miR-29a in fibroblasts and cancer cells in this study. The in situ hybridization to detect the reduction of $m i R-29 a$ signals in these cells will be examined in future studies.

Regulation of miR-29a expression was investigated by chromatin immunoprecipitation assay and in silico analysis. ${ }^{47}$ The promoter region of $m i R-29 a$ contained two putative E-box sites, a Gli-binding site and four nuclear factor-kB-binding sites. These transcription factors bound to these regions and negatively regulated miR-29a expression. ${ }^{47}$ Moreover, TGF- $\beta$ inhibited the expression of the $m i R-29$ family and induced the expression of ECM components. ${ }^{46,48}$ We know that TGF- $\beta$ has a pivotal role in the pathogenesis of IPF by promoting the proliferation, activation and differentiation of epithelial cells and myofibroblasts. ${ }^{1,49}$ Therefore, suppression of the miR-29 family by TGF- $\beta$ is a possible critical event in the progression of IPF, and inhibition of these pathways might be a therapeutic target of the disease.

In conclusion, downregulation of $m i R-29 a$ was observed in clinical specimens of lung cancer and IPF, and miR-29a might contribute to these diseases by targeting LOXL2 and SERPINH1. Overexpression of LOXL2 and SERPINH1 was confirmed in clinical specimens of lung cancer with IPF and they enhance the aggressiveness of these diseases. The identification of novel pathways regulated by the downregulation of miRNA may lead to a better understanding of molecular pathogenesis in lung cancer and pulmonary fibrosis. 

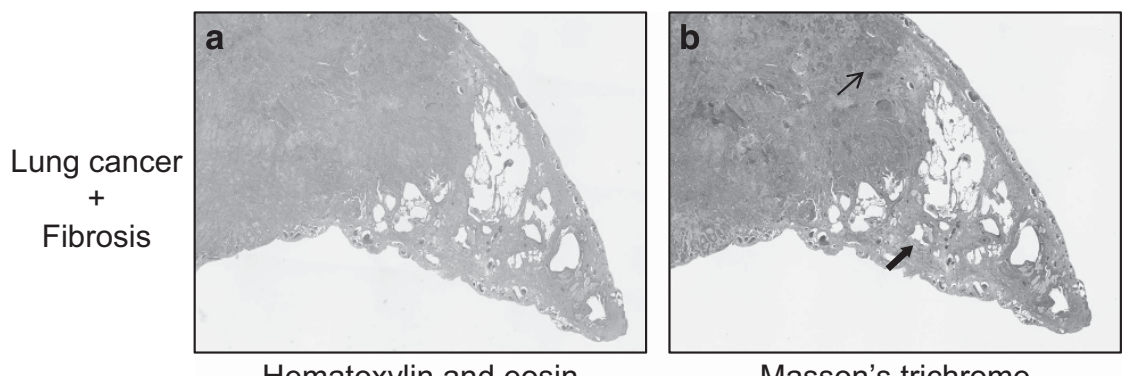

Hematoxylin and eosin

Masson's trichrome
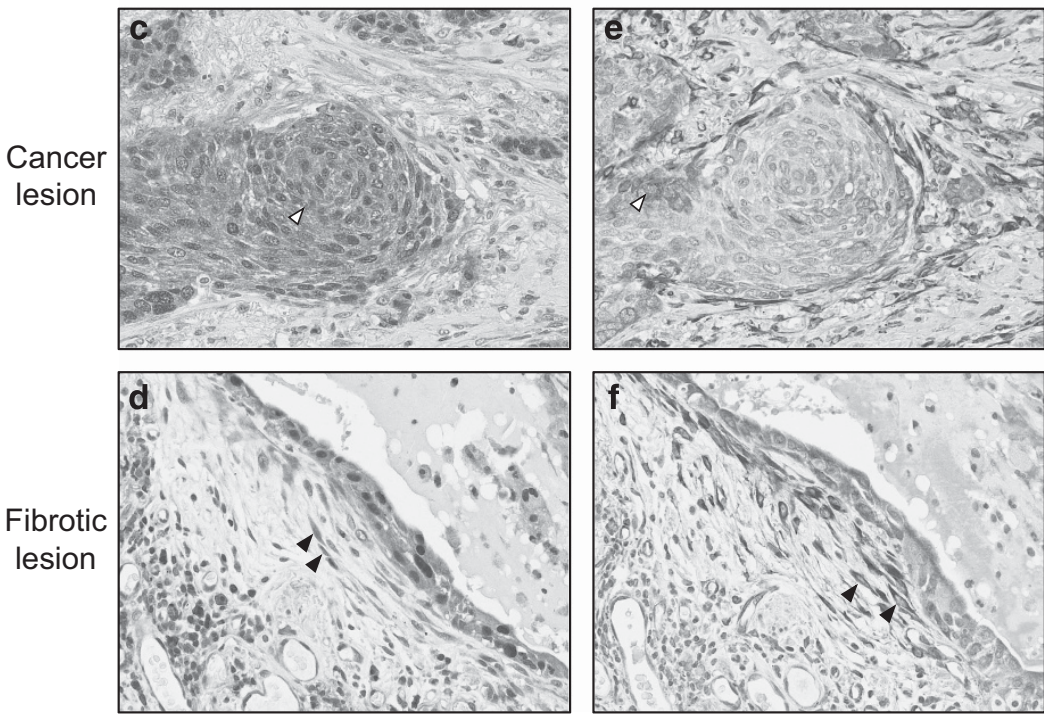

LOXL2

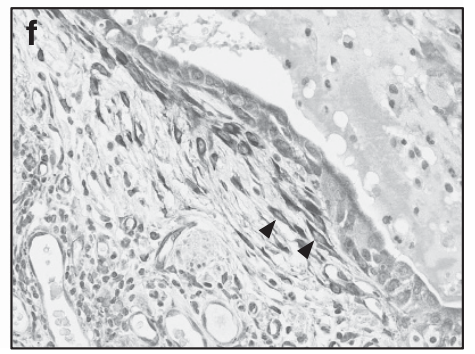

SERPINH1

Figure 6 Immunohistochemical staining of LOXL2 and SERPINH1 in clinical specimens of lung cancer with IPF. (a) Hematoxylin-eosin staining. (b) Masson's trichrome staining. Cancer lesions (thin arrow) and fibrotic lesions (thick arrow) are noted. (c, d) LOXL2 staining. Cancer cells (open arrowheads) and fibroblasts (arrowheads) are noted. (e, f) SERPINH1 staining. Cancer cells (open arrowheads) and fibroblasts (arrowheads) are noted. A full color version of this figure is available at the Journal of Human Genetics journal online.

\section{CONFLICT OF INTEREST}

The authors declare no conflict of interest.

\section{ACKNOWLEDGEMENTS}

We thank Masuki Yamamoto and Masami Sato (Department of General Thoracic Surgery, Graduate School of Medical and Dental Sciences, Kagoshima University, JAPAN) for help with these studies. We thank Joint Research Laboratory, Kagoshima University Graduate School of Medical and Dental Sciences, for the use of their facilities.

1 Wynn, T. A. Integrating mechanisms of pulmonary fibrosis. J. Exp. Med. 208, 1339-1350 (2011).

2 Raghu, G., Collard, H. R., Egan, J. J., Martinez, F. J., Behr, J., Brown, K. K. et al. An official ATS/ERS/JRS/ALAT statement: idiopathic pulmonary fibrosis: evidencebased guidelines for diagnosis and management. Am. J. Respir. Crit. Care Med. 183, 788-824 (2011)

3 Canestaro, W. J., Forrester, S. H., Raghu, G., Ho, L. \& Devine, B. E. Drug treatment of idiopathic pulmonary fibrosis: systematic review and network meta-analysis. Chest 149 , 756-766 (2016)

4 Torre, L. A., Bray, F., Siegel, R. L., Ferlay, J., Lortet-Tieulent, J. \& Jemal, A. Global cancer statistics, 2012. CA Cancer J. Clin. 65, 87-108 (2015).

5 Reck, M., Heigener, D. F., Mok, T., Soria, J. C. \& Rabe, K. F. Management of nonsmall-cell lung cancer: recent developments. Lancet 382, 709-719 (2013).

6 Selman, M., King, T. E. \& Pardo, A. Idiopathic pulmonary fibrosis: prevailing and evolving hypotheses about its pathogenesis and implications for therapy. Ann. Intern. Med. 134, 136-151 (2001).

7 Vancheri, C. Idiopathic pulmonary fibrosis and cancer: do they really look similar? BMC Med. 13, 220 (2015).
8 Hubbard, R., Venn, A., Lewis, S. \& Britton, J. Lung cancer and cryptogenic fibrosing alveolitis. A population-based cohort study. Am. J. Respir. Crit. Care Med. 161, 5-8 (2000).

9 Bartel, D. P. MicroRNAs: genomics, biogenesis, mechanism, and function. Cell 116, 281-297 (2004).

10 Filipowicz, W., Bhattacharyya, S. N. \& Sonenberg, N. Mechanisms of posttranscriptional regulation by microRNAs: are the answers in sight? Nat. Rev. Genet. 9, 102-114 (2008).

11 Hobert, 0 . Gene regulation by transcription factors and microRNAs. Science 319, 1785-1786 (2008).

12 Gao, W., Shen, H., Liu, L., Xu, J., Xu, J. \& Shu, Y. MiR-21 overexpression in human primary squamous cell lung carcinoma is associated with poor patient prognosis. J. Cancer Res. Clin. Oncol. 137, 557-566 (2011).

13 Pandit, K. V., Corcoran, D., Yousef, H., Yarlagadda, M., Tzouvelekis, A., Gibson, K. F. et al. Inhibition and role of let-7d in idiopathic pulmonary fibrosis. Am. J. Respir. Crit. Care Med. 182, 220-229 (2010).

14 Yanaihara, N., Caplen, N., Bowman, E., Seike, M., Kumamoto, K., Yi, M. et al. Unique microRNA molecular profiles in lung cancer diagnosis and prognosis. Cancer Cell 9, 189-198 (2006).

15 Oak, S. R., Murray, L., Herath, A., Sleeman, M., Anderson, I., Joshi, A. D. et al. A micro RNA processing defect in rapidly progressing idiopathic pulmonary fibrosis. PLOS ONE 6. e21253 (2011).

16 Liang, H., Gu, Y., Li, T., Zhang, Y., Huangfu, L., Hu, M. et al. Integrated analyses identify the involvement of microRNA-26a in epithelial-mesenchymal transition during idiopathic pulmonary fibrosis. Cell Death Dis. 5, e1238 (2014).

17 Mataki, H., Seki, N., Chiyomaru, T., Enokida, H., Goto, Y., Kumamoto, T. et al. Tumor-suppressive microRNA-206 as a dual inhibitor of MET and EGFR oncogenic signaling in lung squamous cell carcinoma. Int. J. Oncol. 46, 1039-1050 (2015).

18 Mizuno, K., Seki, N., Mataki, H., Matsushita, R., Kamikawaji, K., Kumamoto, T. et al. Tumor-suppressive microRNA-29 family inhibits cancer cell migration and invasion directly targeting LOXL2 in lung squamous cell carcinoma. Int. J. Oncol. 48, 450-460 (2016). 
19 Nishikawa, R., Goto, Y., Kojima, S., Enokida, H., Chiyomaru, T., Kinoshita, T. et al. Tumor-suppressive microRNA-29s inhibit cancer cell migration and invasion via targeting LAMC1 in prostate cancer. Int. J. Oncol. 45, 401-410 (2014).

20 Yoshino, H., Seki, N., Itesako, T., Chiyomaru, T., Nakagawa, M. \& Enokida, H. Aberrant expression of microRNAs in bladder cancer. Nat. Rev. Urol. 10, 396-404 (2013).

21 Goto, Y., Kurozumi, A., Enokida, H., Ichikawa, T. \& Seki, N. Functional significance of aberrantly expressed microRNAs in prostate cancer. Int. J. Urol. 22, 242-252 (2015).

22 Fukumoto, I., Kikkawa, N., Matsushita, R., Kato, M., Kurozumi, A., Nishikawa, R. et al. Tumor-suppressive microRNAs (miR-26a/b, miR-29a/b/c and miR-218) concertedly suppressed metastasis-promoting LOXL2 in head and neck squamous cell carcinoma. J. Hum. Genet. 61, 109-118 (2016).

23 Yamamoto, N., Kinoshita, T., Nohata, N., Yoshino, H., Itesako, T., Fujimura, L. et al. Tumor-suppressive microRNA-29a inhibits cancer cell migration and invasion via targeting HSP47 in cervical squamous cell carcinoma. Int. J. Oncol. 43, 1855-1863 (2013).

24 Canel, M., Serrels, A., Frame, M. C. \& Brunton, V. G. E-cadherin-integrin crosstalk in cancer invasion and metastasis. J. Cell Sci. 126, 393-401 (2013).

25 Lester, B. R. \& McCarthy, J. B. Tumor cell adhesion to the extracellular matrix and signal transduction mechanisms implicated in tumor cell motility, invasion and metastasis. Cancer Metastasis Rev. 11, 31-44 (1992).

26 Cox, T. R. \& Erler, J. T. Remodeling and homeostasis of the extracellular matrix: implications for fibrotic diseases and cancer. Dis. Model Mech. 4, 165-178 (2011).

27 Lu, P., Takai, K. Weaver, V. M. \& Werb, Z. Extracellular matrix degradation and remodeling in development and disease. Cold Spring Harb. Perspect. Biol. 3 , a005058 (2011)

28 Goldstraw, P., Crowley, J., Chansky, K., Giroux, D. J., Groome, P. A., Rami-Porta, R. et al. The IASLC Lung Cancer Staging Project: proposals for the revision of the TNM stage groupings in the forthcoming (seventh) edition of the TNM Classification of malignant tumours. J. Thorac. Oncol. 2, 706-714 (2007).

29 Mataki, H., Enokida, H., Chiyomaru, T., Mizuno, K., Matsushita, R., Goto, Y. et al. Downregulation of the microRNA-1/133a cluster enhances cancer cell migration and invasion in lung-squamous cell carcinoma via regulation of Coronin1C. J. Hum. Genet. 60, 53-61 (2015)

30 Kinoshita, T., Nohata, N., Hanazawa, T., Kikkawa, N., Yamamoto, N., Yoshino, H. et al. Tumour-suppressive microRNA-29s inhibit cancer cell migration and invasion by targeting laminin-integrin signalling in head and neck squamous cell carcinoma. $\mathrm{Br}$. J. Cancer 109, 2636-2645 (2013).

31 Erler, J. T. \& Weaver, V. M. Three-dimensional context regulation of metastasis. Clin. Exp. Metastasis 26, 35-49 (2009).

32 Kauppila, S., Stenback, F., Risteli, J., Jukkola, A. \& Risteli, L. Aberrant type I and type III collagen gene expression in human breast cancer in vivo. J. Pathol. 186, 262-268 (1998)

33 Matsushita, R., Seki, N., Chiyomaru, T., Inoguchi, S., Ishihara, T., Goto, Y. et al. Tumour-suppressive microRNA-144-5p directly targets CCNE1/2 as potential prognostic markers in bladder cancer. Br. J. Cancer 113, 282-289 (2015).

34 Barker, H. E., Chang, J., Cox, T. R., Lang, G., Bird, D., Nicolau, M. et al. LOXL2 mediated matrix remodeling in metastasis and mammary gland involution. Cancer Res. 71, 1561-1572 (2011).
35 Barker, H. E., Cox, T. R. \& Erler, J. T. The rationale for targeting the LOX family in cancer. Nat. Rev. Cancer 12, 540-552 (2012).

36 Nishikawa, R., Chiyomaru, T., Enokida, H., Inoguchi, S., Ishihara, T., Matsushita, R. et al. Tumour-suppressive microRNA-29s directly regulate LOXL2 expression and inhibit cancer cell migration and invasion in renal cell carcinoma. FEBS Lett. 589, 2136-2145 (2015).

37 Fukumoto, I., Kikkawa, N., Matsushita, R., Kato, M., Kurozumi, A., Nishikawa, R. et al Tumor-suppressive microRNAs (miR-26a/b, miR-29a/b/c and miR-218) concertedly suppressed metastasis-promoting LOXL2 in head and neck squamous cell carcinoma. J. Hum. Genet. 61, 109-118 (2015).

38 Miyata, S., Mizuno, T., Koyama, Y., Katayama, T. \& Tohyama, M. The endoplasmic reticulum-resident chaperone heat shock protein 47 protects the Golgi apparatus from the effects of O-glycosylation inhibition. PLOS ONE 8, e69732 (2013).

39 Maitra, A., lacobuzio-Donahue, C., Rahman, A., Sohn, T. A., Argani, P., Meyer, R. et al. Immunohistochemical validation of a novel epithelial and a novel stromal marker of pancreatic ductal adenocarcinoma identified by global expression microarrays: sea urchin fascin homolog and heat shock protein 47. Am. J. Clin. Pathol. 118, 52-59 (2002).

40 Hirai, K., Kikuchi, S., Kurita, A., Ohashi, S., Adachi, E., Matsuoka, Y. et al. Immunohistochemical distribution of heat shock protein 47 (HSP47) in scirrhous carcinoma of the stomach. Anticancer Res. 26, 71-78 (2006).

41 Amenomori, M., Mukae, H., Sakamoto, N., Kakugawa, T., Hayashi, T., Hara, A. et al. HSP47 in lung fibroblasts is a predictor of survival in fibrotic nonspecific interstitial pneumonia. Respir. Med. 104, 895-901 (2010).

42 Wynn, T. A. \& Ramalingam, T. R. Mechanisms of fibrosis: therapeutic translation for fibrotic disease. Nat. Med 18, 1028-1040 (2012).

43 Cushing, L., Kuang, P. \& Lu, J. The role of miR-29 in pulmonary fibrosis. Biochem. Cell Biol. 93, 109-118 (2015).

44 Cushing, L., Kuang, P. P., Qian, J., Shao, F., Wu, J., Little, F. et al. miR-29 is a major regulator of genes associated with pulmonary fibrosis. Am. J. Respir. Cell Mol. Biol. 45, 287-294 (2011).

45 Fang, Y., Yu, X., Liu, Y., Kriegel, A. J., Heng, Y., Xu, X. et al. miR-29c is downregulated in renal interstitial fibrosis in humans and rats and restored by HIF-alpha activation. Am. J. Physiol. Renal Physiol. 304, F1274-F1282 (2013).

46 Roderburg, C., Urban, G. W., Bettermann, K. Vucur, M., Zimmermann, H., Schmidt, S. et al. Micro-RNA profiling reveals a role for miR-29 in human and murine liver fibrosis. Hepatology 53, 209-218 (2011).

47 Mott, J. L., Kurita, S., Cazanave, S. C., Bronk, S. F., Werneburg, N. W. \& Fernandez-Zapico, M. E. Transcriptional suppression of mir-29b-1/mir-29a promoter by c-Myc, hedgehog, and NF-kappaB. J. Cell Biochem. 110, 1155-1164 (2010).

48 Maurer, B., Stanczyk, J., Jungel, A., Akhmetshina, A., Trenkmann, M., Brock, M. et al. MicroRNA-29, a key regulator of collagen expression in systemic sclerosis. Arthritis Rheum. 62, 1733-1743 (2010).

49 Xaubet, A., Marin-Arguedas, A., Lario, S., Ancochea, J., Morell, F., Ruiz-Manzano, J. et al. Transforming growth factor-betal gene polymorphisms are associated with disease progression in idiopathic pulmonary fibrosis. Am. J. Respir. Crit. Care Med. 168, 431-435 (2003).

Supplementary Information accompanies the paper on Journal of Human Genetics website (http://www.nature.com/jhg) 